\title{
Facebook Como Espacio de Expresión Emocional de los Adolescentes en Morelia, México
}

\author{
Lic. Anaid Calderón-Hernández, \\ Dr. Salvador Madrigal-Moreno, \\ Dra. Flor Madrigal-Moreno,
}

Universidad Michoacana de San Nicolás de Hidalgo, Michoacán, México

\section{Resumen}

Esta investigación tuvo como objetivo identificar la utilización de Facebook como medio de expresión emocional en adolescentes de educación secundaria de Morelia, México; así como conocer la emoción predominante a través de los usos, gratificaciones y necesidades que se satisfacen al utilizar la plataforma. Se empleó la Teoría de Usos y Gratificaciones (TUG) y el esquema de interdependencias de la TUG. Es una investigación de enfoque mixto, no experimental, transeccional. Los resultados señalan que los estudiantes han incorporado a Facebook en sus vidas cotidianas. Llevan perteneciendo a la plataforma en promedio tres años, accediendo diariamente de treinta minutos a tres horas. Se confirma que hacen uso de Facebook como un espacio en donde expresan sus emociones/sentimientos, y que los contenidos, positivos o negativos, afectan en sus estados emocionales.

Palabras clave: Facebook, adolescencia, emociones. 


\title{
Facebook as a Space for Emotional Expression of Teenagers in Morelia, Mexico
}

\author{
Lic. Anaid Calderón-Hernández, \\ Dr. Salvador Madrigal-Moreno, \\ Dra. Flor Madrigal-Moreno,
}

Universidad Michoacana de San Nicolás de Hidalgo, Michoacán, México

\begin{abstract}
This research had the purpose to identify the use of Facebook as a mean of emotional expression in teenagers of High School in Morelia, Mexico; as well as to know the prevailing emotion through the uses, gratifications, and needs that the young people experiment using the platform. The theory used was the Theory of Uses and Gratifications (TUG) and the scheme of the interdependencies of the TUG. It is a mixed approach research, nonexperimental, transactional. The results indicate that students have incorporated Facebook into their daily lives. They have been using the platform on average three years, accessing daily from thirty minutes to three hours. It is confirmed that they use Facebook as a space where they express their emotions/ feelings, and that the positive or negative contents, affect in their emotional states.
\end{abstract}

Keywords: Facebook, teenagers, emotions.

\section{Introducción}

Las cosas han cambiado mucho a través de los años, no es lo mismo ser un adolescente hoy en día que como se era en la década pasada. Las personas ya no se hablan por teléfono, sino que chatean, a los jóvenes ya no les interesa gastar en un mensaje, prefieren dejar un inbox en Facebook o cualquier otra plataforma. Actualmente se vive en una era digital donde la tecnología, el Internet, y las redes sociales se han combinado en una sola para convertirse en herramientas muy poderosas, vitales e influyentes en la sociedad, generando un gran impacto, principalmente en los jóvenes quienes las han incorporado desde muy temprana edad en su vida.

Una de las principales plataformas digitales a nivel mundial es Facebook, la cual ofrece un abanico de opciones: contactar con amigos y familiares, conocer gente de otra parte del mundo, compartir fotos, videos, jugar, chatear, etc. También permite que sus usuarios la utilicen como un 
medio de desahogo emocional, principalmente en los adolescentes; los cuales atraviesan una época de cambios significativos, no sólo en lo físico, también en lo psicológico. El expresar sus problemas o decepciones amorosas; momentos de felicidad, alegría, inquietudes, enojos, etc., por medio de un ordenador puede resultar de gran ayuda para los jóvenes. En esto se centra la presente investigación, cuyo objetivo principal es identificar la utilización de Facebook como medio de expresión emocional en los adolescentes de educación secundaria; así como conocer la emoción predominante a través de los usos, gratificaciones y necesidades que satisfacen al utilizar Facebook.

\section{Marco Referencial}

Lo virtual es cada día más real. Gran parte de los adolescentes que usan Facebook no sólo lo hacen para compartir su información, chatear, chismear, comentar o jugar, sino que también lo emplean para expresar sus emociones. Lo utilizan como si fuera un diario personal en el que plasman lo que piensan y lo que sienten. Como fue mencionado anteriormente, la adolescencia es una etapa de cambios; entre ellos se encuentran los cambios emocionales. Referente a ello, Durán \& Basabe (2013) concluyeron que una buena parte de los usuarios ventilan sus intimidades en esta red social y son capaces de hacer confidencias, expresar una gama de intimidades y emociones que en el contexto real es poco probable que se den. Siguiendo esta línea, Ochoa \& Uribe (2015) realizaron un estudio sobre la interacción social mediada por Facebook, los resultados arrojaron que gran parte del contenido de las actualizaciones de estado tenían algún sentido emocional, especialmente por las mujeres, quienes hablaron de aspectos de personalidad como la timidez y de la autoestima. Los hombres manifestaron que prefieren expresar sus emociones en persona pues así pueden recibir calidez y apoyo, lo cual los hace sentir bien y tienen una sensación de desahogo; no obstante, también lo hacen por Facebook y reconocen que les resulta más fácil hacerlo así, pues genera también una sensación de desahogo y disminuye la tensión de expresarse frente a una persona.

Por otra parte, Ayala (2012) determinó que la manifestación favorita que expresan los adolescentes en su estatus es sobre frases o citas textuales y en segundo lugar sobre sus estados de ánimo; predominó el negativo, seguido por el positivo y al final el neutral. A diferencia de lo que concluyeron, Durán \& Basabe (2013) donde la emoción predominante fue la positiva, seguida de la negativa. De igual forma, Serrano (2016) estableció que las redes sociales no sólo despiertan emociones en sus usuarios y sirve de cauce para la expresión de los afectos, sino que también influyen en el modo en que dicho afecto se modula y despliega, así como en la configuración de la identidad de la persona. 
La expresión personal se da principalmente a través de la sección conocida como estatus que en la misma plataforma se promueve con la pregunta: ¿En qué estás pensando? En este apartado los usuarios típicamente escriben sus pensamientos, estados de ánimo e ideas que buscan reflejar y dar a conocer a los demás (Ayala, 2013: 32). Al hablar de formas de expresión, no sólo se hace referencia a ideas o pensamientos que tienen los adolescentes, sino también se refiere a cómo es manejado el lenguaje. No sólo se expresa lo que se siente, ni lo que se piensa a través de las palabras, se hace también por medio de imágenes, emoticones, vídeos, etc. (Torres \& Vega, 2009: 34).

Otras opciones que tiene el usuario de expresar sus emociones en esta red social, es por medio del apartado sentimiento/ actividad, aquí el consumidor tiene la posibilidad de elegir entre 94 emociones la que más se relacione con su estado de ánimo. También por medio de la relativamente nueva función de Facebook, conocida como reacciones el usuario puede expresar la emoción que puede provocar algunas de las publicaciones de sus contactos. Resulta interesante que México sea el líder a nivel mundial del ranking de países que más utilizan esta opción. Esto quiere decir que el usuario mexicano efectivamente expresa sus emociones a través de Facebook. Especialmente en la etapa de la adolescencia que está cargada de sufrimiento, estrés, pasión, rebeldía (Hall en Morris \& Maisto: 354) y a través de la web 2.0 encuentran un medio para expresar sus sentimientos que no son virtuales, sino reales. Tal y como se menciona en un estudio publicado en la revista Psychological Science, realizado por Joanne Wood y Amanda Forest: “[...] la gente [...] se comporta de manera diferente a la hora de expresar sus emociones cara a cara, y percibe la red social como un lugar seguro para evitar situaciones sociales violentas o embarazosas, por lo que se comunican más online" (en Valderrama, 2013: 43).

De acuerdo con las investigaciones que se han hecho referentes al tema de Facebook como medio de expresión emocional, se puede observar que es un fenómeno que está sucediendo en la actualidad, donde efectivamente esta plataforma es utilizada para expresar emociones, satisfaciendo las necesidades afectivas de los jóvenes.

\section{Teoría de Usos y Gratificaciones aplicada en Facebook}

Aunque la Teoría de los Usos y las Gratificaciones fue creada en el contexto de los medios tradicionales, algunos autores como Gilder (en González, 2013: 07) ya se habían cuestionado sobre cómo afectaría a la cultura un híbrido entre televisión y ordenador. Asimismo, los autores Papacharissi \& Rubin (en West \& Turner, 2005: 363) hicieron una investigación sobre Internet basada en esta teoría. Concluyeron que las personas tienen cinco motivos principales para utilizar Internet, y el más importante de ellos era buscar información, mientras que las que se sienten más inseguras recurren a 
este medio por motivos sociales. Y, sobre todo, llegaron a la conclusión de que la Teoría de Usos y Gratificaciones ofrece un marco adecuado para estudiar los nuevos medios de comunicación (González, 2013: 07).

La Teoría de Usos y Gratificaciones postula que cada individuo es activo y selecciona los estímulos a los que quiere responder. Parte de la idea de que todas las personas tienen necesidades que buscan permanentemente satisfacer, y en ese sentido los medios les brindarían cierto tipo de gratificaciones. Esto tiene una intención específica y se deriva de motivaciones personales y sociales. El individuo cuenta con una amplia gama de medios de comunicación como alternativas funcionales que cubran sus necesidades, las cuales están divididas en cuatro categorías (Lozano, 2007). Katz, Gürevitch y Hass (en Pascual, 2004: 198) singularizaron el tipo de recompensas que obtiene el individuo al usar los medios:

-Cognitivas: derivadas de la necesidad de ampliar los conocimientos y la comprensión del entorno.

-Afectivas: derivadas de la necesidad de fortalecimiento de las experiencias emocionales, agradables y estéticas.

-De integración personal: reforzar la credibilidad, la confianza y el estatus.

-De integración social: reforzar las conexiones con la familia, amigos.

-De evasión o escape: derivadas de la necesidad de liberar las tensiones, reducir la ansiedad y el deseo de diversión.

Mientras las gratificaciones de los medios de comunicación se dividen en cuatro categorías: diversión, relaciones sociales, identidad personal y vigilancia, las cuales están presentes en las redes sociales, específicamente en Facebook. De manera que su uso puede gratificar al individuo de las siguientes maneras:

-Vigilancia: en Facebook el internauta está en constante vigilancia; revisa su perfil, el de sus contactos y la sección de noticias para encontrar información y mantenerse actualizado sobre las últimas publicaciones o noticias que se están generando.

-Diversión: las personas emplean su tiempo libre en la plataforma para entretenerse, divertirse, escapar de sus problemas, liberación emocional, entre otros.

-Identidad personal: las redes sociales son parte de la formación de la identidad personal de los adolescentes. Facebook es un tipo de diario personal virtual en donde el usuario expone pensamientos, gustos, hábitos, emociones, etc.; en sí experimenta y se muestran rasgos de su personalidad, se va construyendo una identidad virtual. El usuario se identificará o sentirá algún tipo de unión con otros por los gustos o intereses que tienen en común. 
Básicamente, las redes sociales les ayudarán a reforzar, tener valoración social, control sobre sí mismos, crear vínculos y configurar sus propias identidades.

-Relaciones sociales: Evidentemente uno de los principales motivos para hacer una cuenta en Facebook es el conocer o mantener una relación con nuevas personas. Facilita la comunicación con los seres queridos, a ganar empatía social y ayuda en la interacción social como tema de conversación.

De tal forma que las redes sociales efectivamente están respondiendo a la necesidad del ser humano para comunicarse y socializarse. Por lo tanto, los objetivos del modelo de usos y gratificaciones se cumplen en las redes sociales, en cuanto a las necesidades de interacción; tanto las reales como las relacionadas a las expectativas creadas. Esto último se refiere a la capacidad de multidirigir mensajes a diferentes personas y de recibir una respuesta rápida, potenciándose la comunicación (Bonilla \& Vargas, 2012: 34).

\section{Metodología}

La primera parte de esta investigación estuvo conformada por una revisión de literatura que consistió en reunir y analizar diversos libros, periódicos, informes, tesis, ponencias y artículos científicos donde se ha investigado dicho fenómeno en diversos contextos. Esto permitió establecer como base teórica a la Teoría de Usos y Gratificaciones planteada por los teóricos Elihu Katz, Jay G, Blumler y Michael Gürevitch.

En este caso la población que se eligió para llevar la recolección de datos estuvo conformada por adolescentes estudiantes de educación pública de nivel secundaria de Morelia, México. La muestra del estudio fue por conveniencia y estuvo integrada por 469 alumnos con una confiabilidad de $95 \%$ y un error de $4.5 \%$, superando el $95 \%$ de confiabilidad y $5 \%$ de error que es el estándar en las investigaciones de las ciencias sociales cuando el universo es muy grande o desconocido (Raosoft, 2018).

La investigación es mixta de tipo no experimental y transeccional. Para la recuperación de información primaria se utilizó el cuestionario. El cuestionario diseñado fue adaptado y tiene como base investigaciones referentes a los Usos y Gratificaciones de las redes sociales en los adolescentes, tales como las de Bedoya \& Bustamante (2015), Rivadeneira (2016), López, López \& Galán, (2013), García \& Delval (2010), Molina \& Toledo (2014) Bonilla \& Vargas (2012) y Hernández \& Castro (2014). También se basó en el esquema de las interdependencias de la Teoría de Usos y Gratificaciones presentado por el autor Lorenzo Vilches (en Sosa \& Arcila, 2013: 38).

El cuestionario aplicado se dividió en cuatro apartados. El primer bloque de la prueba Perfil de encuestado permitió conocer y establecer las 
características demográficas de los encuestados con su edad, grado escolar, género y turno.

El segundo apartado de la encuesta Conectividad a Internet $y$ Facebook lo integraron un total de ocho preguntas. Las primeras cuatro fueron dicotómicas y las siguientes cuatro de opción múltiple.

El tercer apartado del apartado Necesidades estuvo conformado por 41 ítems, divididos en cinco categorías: necesidades cognitivas, necesidades de integración personal, necesidades de integración social, necesidades de evasión y necesidades afectivas. Por último, la cuarta sección Gratificaciones lo constituyeron nueve satisfacciones que Facebook brinda. Los elementos que integraron ambos apartados se presentan en escala tipo Likert. Es fundamental señalar que una de las características que debió contener el cuestionario es la validez y fiabilidad. Para ello se utilizó el software estadístico, IBM SPSS25. Por medio del Alfa de Cronbach, el instrumento de recolección de datos aplicado tuvo un coeficiente de 0.881 , lo cual establece que los ítems miden un mismo constructo y que están altamente correlacionados entre sí.

\section{Resultados}

\section{Usos y necesidades que satisfacen en Facebook, los adolescentes en México.}

Los cuestionarios se aplicaron a 611 estudiantes de las cuales 142 fueron desechadas debido a diferentes inconsistencias, quedando un total de 469 cuestionarios debidamente contestados.

Con relación al género, la participación de los hombres fue ligeramente mayor con el $50.3 \%$ frente al $49.7 \%$ de las mujeres; sin embargo, esto no afectó en la investigación ya que los resultados no estuvieron enfocados con relación al género.

Por otro lado, los resultados registrados indican que, en su mayoría, los estudiantes tienen un dispositivo móvil (computadora/laptop/tableta) e Internet en su casa. Sin embargo, hay una parte que no cuenta con ninguno de estos dispositivos (Gráfica 1) lo cual indica que existe una brecha tecnológica entre este sector.

Gráfica 1- Disposición de computadora, laptop, tableta

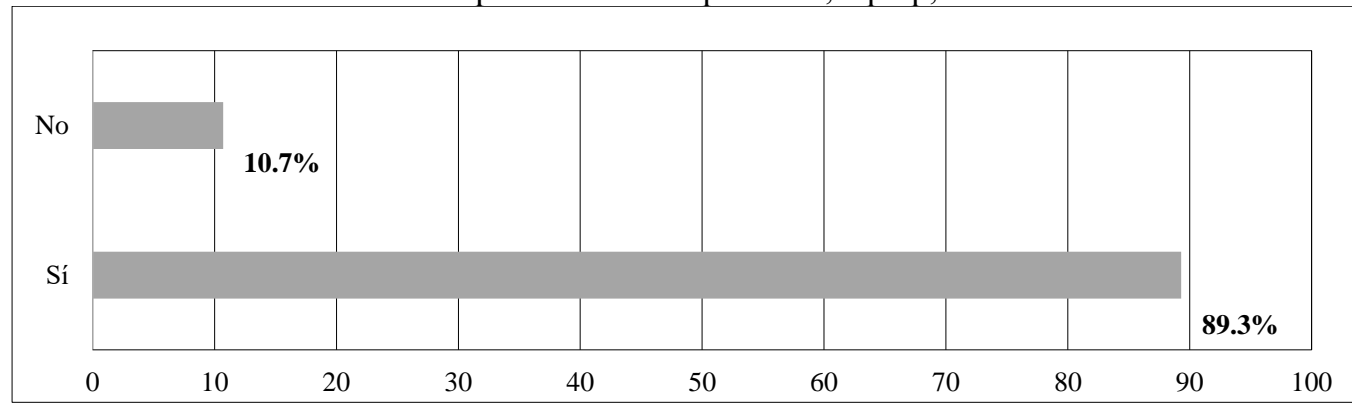

Fuente: Elaboración propia a partir de los resultados obtenidos. 
Se determinó que los adolescentes han incorporado a Facebook en sus vidas cotidianas. Los jóvenes acceden diariamente a la red social a través de su celular por un tiempo que va de treinta minutos a tres horas. La información detallada por grado escolar se presenta en la gráfica 2. Cabe destacar que en promedio llevan siendo miembros de Facebook durante tres años. No obstante, el $43.6 \%$ lleva de cuatro a siete años registrado en la red social.

Gráfica 2- Años en escolar Facebook/por grado

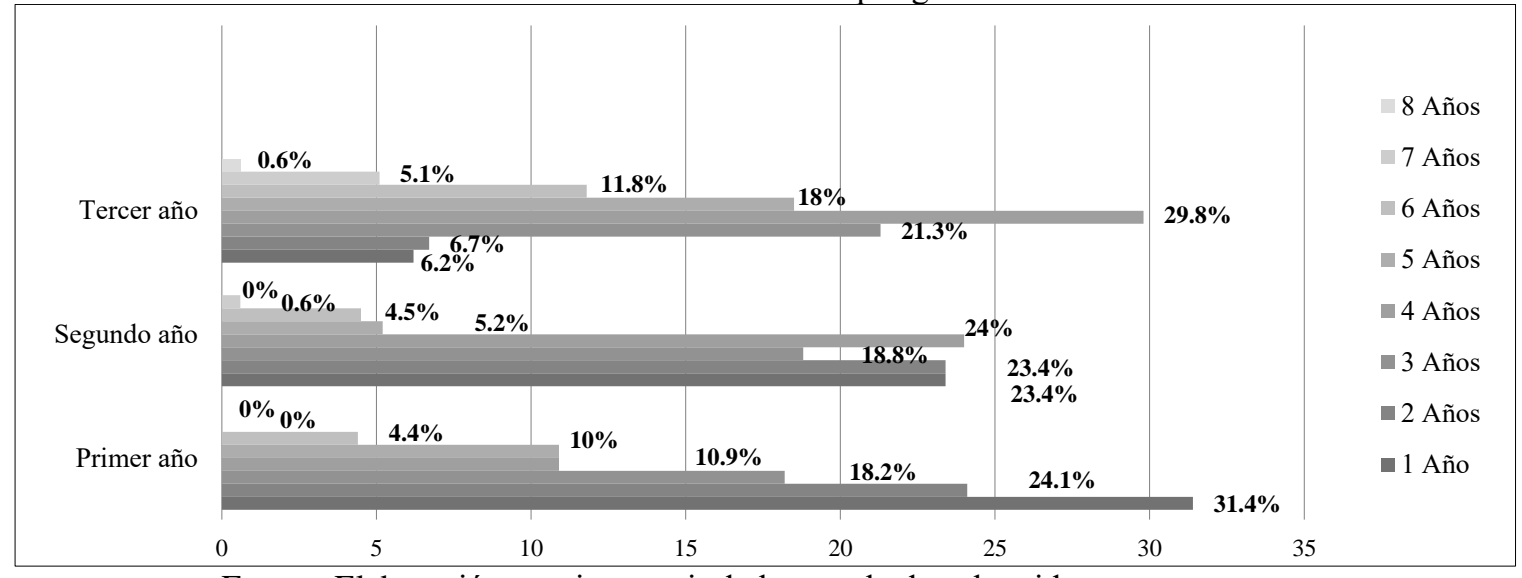

Fuente: Elaboración propia a partir de los resultados obtenidos.

Pero todo ello con el consentimiento de sus padres, ya que la mayoría señaló que sus papás estaban enterados de que son miembros de la plataforma, aun cuando la edad mínima requerida para crear un perfil en esta red social es de 14 años.

La necesidad que más satisfacen los estudiantes por medio de Facebook pertenece a la cognitiva y la menor corresponde a la de evasión.

Perteneciente a la categoría de necesidades de integración personal, el uso que más le dan a Facebook los adolescentes es el de ver y compartir memes (4.1 puntos de 5 posibles con la escala de Likert). Éstos se han convertido en un medio de expresión muy popular en los medios digitales y ellos disfrutan de crearlos, consumirlos y reproducirlos en Facebook, especialmente los hombres. De igual manera a los encuestados les gusta compartir imágenes suyas (más las mujeres).

Asimismo, la red social representa un medio informativo para los jóvenes, ya que un gran porcentaje lo utilizan para mantenerse informados acerca de lo que pasa en el mundo y en su alrededor. En gran medida les gusta transmitir con sus amigos o conocidos la información captada en la red social. Es importante destacar que conforme el adolescente va creciendo, el interés por mantenerse informado también aumenta. Además, se identificó que una cuarta parte de los encuestados se sienten más cómodos y desinhibidos comunicándose en el mundo virtual que en el real, principalmente las mujeres. También se identificó que los estudiantes alivian el estrés provocado por la 
escuela o las tareas del hogar a través de Facebook, el 62.6\% afirmó utilizarlo para relajarse después de realizar sus deberes.

Con relación a lo afectivo, se registraron resultados importantes. Uno de ellos es que los adolescentes ya no sólo usan la red social para comunicarse con sus seres queridos o divertirse, sino que también se ha convertido en un medio de expresión emocional. La mayoría de los jóvenes eligieron estar de acuerdo en que a través de Facebook expresan sus sentimientos/emociones, se contabilizó una media de 3.6 puntos. Los que más comparten sus emociones son los alumnos de tercer grado (Tabla 1). Cabe destacar que las mujeres son quienes más utilizan Facebook para este motivo. Asimismo, las emociones positivas superaron a las emociones negativas, los estudiantes manifestaron que en las publicaciones de sus contactos predominan las emociones de amor, felicidad, alegría, etc.

Tabla 1 - Facebook como medio de expresión emocional/por grado escolar

\begin{tabular}{|c|c|c|c|c|c|c|c|c|}
\hline & & & $\begin{array}{c}\text { Muy en } \\
\text { desacuerdo }\end{array}$ & $\begin{array}{c}\text { En } \\
\text { desacuerdo }\end{array}$ & $\begin{array}{c}\text { Ni de } \\
\text { acuerdo ni } \\
\text { en } \\
\text { desacuerdo }\end{array}$ & $\begin{array}{c}\text { De } \\
\text { acuerdo }\end{array}$ & $\begin{array}{l}\text { Muy de } \\
\text { acuerdo }\end{array}$ & Total \\
\hline \multirow{6}{*}{$\begin{array}{l}\text { Grado } \\
\text { escolar }\end{array}$} & \multirow{2}{*}{$\begin{array}{l}\text { 1er } \\
\text { año }\end{array}$} & $\mathrm{N}^{\circ}$ & 4 & 12 & 26 & 69 & 26 & 137 \\
\hline & & $\%$ & $0.9 \%$ & $2.6 \%$ & $5.5 \%$ & $14.7 \%$ & $5.5 \%$ & $29.2 \%$ \\
\hline & \multirow{2}{*}{$\begin{array}{l}2^{\circ} \\
\text { año }\end{array}$} & $\mathrm{N}^{\circ}$ & 4 & 19 & 31 & 70 & 30 & 154 \\
\hline & & $\%$ & $0.9 \%$ & $4.1 \%$ & $6.6 \%$ & $14.9 \%$ & $6.4 \%$ & $32.8 \%$ \\
\hline & \multirow{2}{*}{$\begin{array}{l}\text { 3er } \\
\text { año }\end{array}$} & $\mathrm{N}^{\circ}$ & 9 & 20 & 39 & 83 & 27 & 178 \\
\hline & & $\%$ & $1.9 \%$ & $4.3 \%$ & $8.3 \%$ & $17.7 \%$ & $5.8 \%$ & $38.0 \%$ \\
\hline \multirow{2}{*}{\multicolumn{2}{|c|}{ Total }} & $\mathrm{N}^{\circ}$ & 17 & 51 & 96 & 222 & 83 & 469 \\
\hline & & $\%$ & $3.6 \%$ & $10.9 \%$ & $20.5 \%$ & $47.3 \%$ & $17.7 \%$ & $100.0 \%$ \\
\hline
\end{tabular}

Fuente: Elaboración propia a partir de los resultados obtenidos.

Por otra parte, dentro de esta categoría se registró que para los adolescentes es de suma importancia recibir me gusta en lo que publican en Facebook, ya que esto demuestra aceptación y aprobación por parte de sus amigos. El tenerlos o no tenerlos generará un cambio en sus estados de ánimo. En promedio este ítem tuvo 3.5 puntos, siendo los de tercer año quienes se ubicaron en el primer lugar (Gráfica 3). Se observó un incremento de porcentaje conforme aumentaban las edades. 
Gráfica 3 - El recibir me gusta cambia mi estado emocional

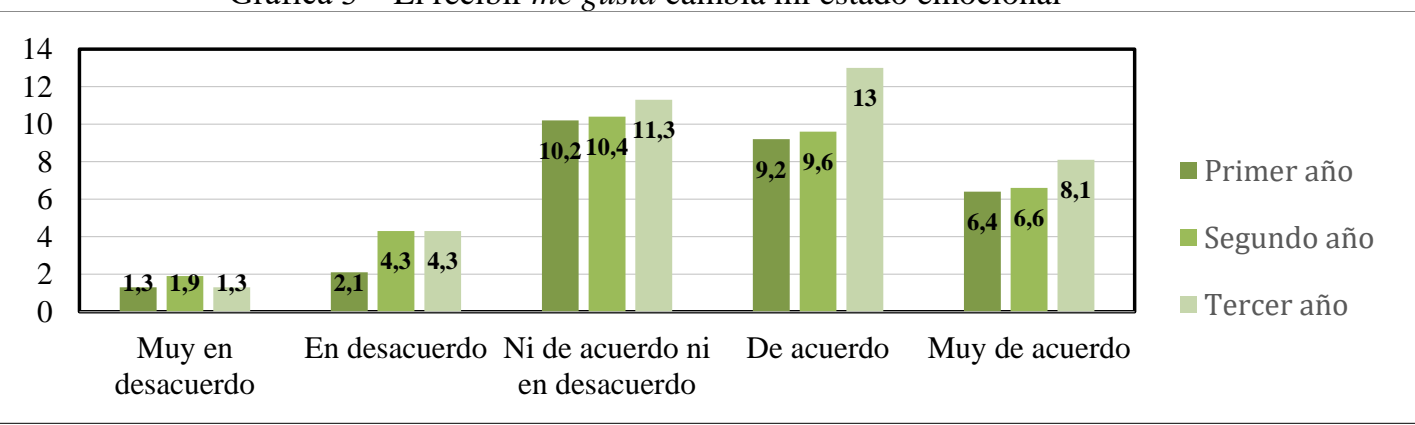

Fuente: Elaboración propia a partir de los resultados obtenidos.

Entre otros datos relevantes, se identificó que efectivamente el ver publicaciones/imágenes/ videos con contenido positivo cambia el estado emocional en los estudiantes (3.6 puntos). De igual forma sucedió con el contenido negativo, se develó que los jóvenes cambian de estado emocional al ver publicaciones/imágenes/videos con contenido negativo, con una media fue del 3.5 puntos.

Por último, es conveniente señalar que las reacciones de Facebook (me encanta, me divierte, me asombra, me enoja, me entristece) ayudan a los adolescentes a expresar mejor su sentir respecto a una publicación, su promedio fue del 3.8 puntos. Las mujeres son quienes más las utilizan. Las dos reacciones preferidas por los estudiantes fueron: me encanta (3.8 puntos) y me divierte (3.3 puntos). Ambas clasificadas dentro de las emociones positivas/agradables. Mientras que las reacciones menos usadas pertenecen a las emociones negativas, como lo son: me entristece (3.5 puntos) y me enoja (3.3 puntos), en medio se posicionaron las neutras con me asombra (3.2 puntos).

Facebook y la gratificación en los adolescentes estudiantes de secundaria.

Los resultados obtenidos indican que los alumnos efectivamente satisfacen sus necesidades con la red social y obtienen gratificaciones de ella. Como se explicó anteriormente, estas gratificaciones están divididas en cuatro categorías: diversión, relaciones personales, identidad personal y vigilancia.

La categoría de vigilancia fue la que obtuvo mayor puntaje con 3.8 puntos. Esta variable estuvo constituida por tres ítems relacionados con 1) mantenerse informados sobre eventos de mis contactos (19GV1), 2) enterarse de promociones de productos de mi interés (19GV2), 3) permanecer informados sobre lo que acontece en el mundo (19GV3) y se presentan en la tabla 2 . 
Tabla 2- Facebook y sus gratificaciones como medio de vigilancia / promedios de categoría

\begin{tabular}{|c|c|c|c|}
\hline & $\begin{array}{c}\text { 19GV1.- Facebook me } \\
\text { mantiene informado sobre } \\
\text { las actividades o eventos } \\
\text { sociales de mis contactos }\end{array}$ & $\begin{array}{c}\text { 19GV2.- En Facebook me } \\
\text { entero de promociones y } \\
\text { descuentos de productos } \\
\text { de mi interés }\end{array}$ & $\begin{array}{c}\text { 19GV3.- Facebook } \\
\text { me informa sobre } \\
\text { lo que pasa en el } \\
\text { mundo }\end{array}$ \\
\hline Media & $\mathbf{3 . 8}$ & $\mathbf{3 . 7}$ & $\mathbf{3 . 9}$ \\
\hline
\end{tabular}

Fuente: Elaboración propia a partir de los resultados obtenidos.

Las relaciones sociales fue la segunda categoría elegida por los adolescentes, tuvo un promedio de 3.7 puntos. La plataforma es un medio ideal para la construcción y fortalecimiento de vínculos sociales. El interactuar con personas nuevas y el hacer amistades son recompensas que Facebook brinda a los alumnos. El permanecer en contacto con familiares/amigos fue la gratificación que obtuvo mayor puntaje en la encuesta con 4.2 puntos.

Divertirse, relajarse y liberarse emocionalmente son otras de las gratificaciones que reciben los estudiantes de la red social. La variable de diversión obtuvo un promedio de 3.6 puntos.

Esta variable estuvo constituida por tres ítems relacionados con 1) Facebook me entretiene (19GD1), 2) escapar de la rutina (19GD2), 3) expresar mis estados de ánimo (19GD3) y se presentan en la tabla 3. La gratificación de entretenimiento y desahogo emocional en gran medida fueron seleccionadas por los alumnos.

Tabla 3 - Facebook y sus gratificaciones como medio de diversión / promedios de categoría

\begin{tabular}{|c|c|c|c|}
\hline & $\begin{array}{c}\text { 19GD1.- Facebook } \\
\text { me entretiene }\end{array}$ & $\begin{array}{c}\text { 19GD2.- En Facebook } \\
\text { escapo de mi rutina }\end{array}$ & $\begin{array}{c}\text { 19GD3.- En Facebook } \\
\text { expreso mis estados de } \\
\text { ánimo }\end{array}$ \\
\hline Media & $\mathbf{4 . 0}$ & $\mathbf{3 . 1}$ & $\mathbf{3 . 8}$ \\
\hline
\end{tabular}

Fuente: Elaboración propia a partir de los resultados obtenidos.

La categoría identidad personal presentó el menor promedio de todas (2.2 puntos), los estudiantes no recibieron gratificaciones en esta variable. En todos sus ítems los alumnos se mostraron en desacuerdo (Tabla 4).

Tabla 4. Facebook y sus gratificaciones en la identidad personal / promedios categoría

\begin{tabular}{|c|c|c|c|}
\hline & $\begin{array}{c}\text { 20GI1.- Facebook me } \\
\text { ayuda a tomar decisiones }\end{array}$ & $\begin{array}{c}\text { 20GI2.- Facebook sube mi } \\
\text { estatus social/ soy más } \\
\text { popular }\end{array}$ & $\begin{array}{c}\text { 20GI3. En Facebook cambia mi } \\
\text { forma de comportarme }\end{array}$ \\
\hline Media & $\mathbf{2 . 1}$ & $\mathbf{2 . 5}$ & $\mathbf{2 . 2}$ \\
\hline
\end{tabular}

Fuente: Elaboración propia a partir de los resultados obtenidos.

\section{Conclusiones}

A partir de las cifras, resultados extraídos del cuestionario y el análisis bibliográfico, se comprueban los objetivos que fueron formulados al inicio de esta investigación. Efectivamente, Facebook, gratifica a los adolescentes que se encuentran en una edad donde se producen una serie de cambios físicos, socioculturales, psicológicos y emocionales. Buscan activamente satisfacer 
sus necesidades a través de la red social, utilizándola como apoyo emocional. Los jóvenes han incorporado la plataforma en sus vidas cotidianas, no sólo como una forma de ocio o entretenimiento, sino como un espacio en el cual pueden exponer sus emociones.

Como menciona la Teoría de Usos y Gratificaciones: la audiencia (en el ámbito de las redes sociales, usuarios) es activa e identifica cuáles necesidades, motivaciones y expectativas quiere satisfacer a través de Facebook, quien le proporcionará al usuario diversas gratificaciones de acuerdo con la selección de mensajes que éste elija activamente.

Esta investigación permitió establecer que esta plataforma además de traer cambios dentro de lo cultural, laboral y educativo, también lo ha hecho en lo psicosocial, demostrando que aparte de ser una potente herramienta de comunicación, va a permitir que los adolescentes se sientan cómodos compartiendo sus estados de ánimo a través de un ordenador. Llamó la atención que para los jóvenes sea de gran importancia el recibir me gusta en sus publicaciones, un simple clic en Facebook puede cambiar su estado emocional. Conforme van creciendo, aumenta la importancia de tener me gusta en lo que publican. En esta misma línea, los contenidos que ven los alumnos, ya sean negativos o positivos, van a provocar un efecto en ellos, ocasionando un cambio en su estado emocional. Las emociones positivas superaron a las negativas y las reacciones favoritas fueron: me encanta y me divierte.

Se determinó que la necesidad que más satisfacen pertenece a la cognitiva y la menor corresponde a la de evasión.

En torno a las gratificaciones se identificó que mantenerse en contacto con familiares/amigos lejanos fue la favorita. Sin embargo, la variable de gratificación que mayormente reciben es la de vigilancia.

Algunas limitaciones en el desarrollo de este trabajo de investigación se centran en que fue un diseño transeccional; por lo tanto, este resultado no puede implicar una relación entre el uso de Facebook y la expresión emocional de los adolescentes en Morelia, México. Sin embargo, se analizó la asociación entre el uso de Facebook y la Teoría de Usos y Gratificaciones como medio de expresión, por lo tanto, el presente estudio podría ilustrar sobre algunos usos de Facebook que influyen en la expresión emocional de los adolescentes en Morelia, México.

En futuras investigaciones se podría replicar esta investigación en diferentes contextos. Por otra parte, también se podría complementar la investigación dando un seguimiento netnográfico e investigar los comportamientos de los adolescentes dentro de la plataforma, saber la clase de necesidades que satisfacen con Facebook, los diversos usos que le dan, el tipo de contenido que publican, las emociones que predominan durante la 
etapa de la adolescencia y si efectivamente la red social sirve como un medio para desahogarse, reforzando y contrastando los resultados presentados.

\section{References:}

1. Ayala, M. (2013). La impersonalidad aceptada del discurso en Facebook: el estatus más común entre los jóvenes. Fonseca Journal of communication(6), 32.

2. Bedoya, V., \& Bustamante, J. (2015). Relacion de la red social Facebook con la construccion de la identidad, en adolescentes escolarizados entre 15 y 19 años de la zona urbana del municipio de San Jerónimo. Medellín.

3. Bonilla, I., \& Vargas, E. (2012). Estudio exploratorio del uso y riesgos de las redes sociales por parte de los niños y niñas en edad escolar del Área Metropolitana: caso de la escuela Juan Rafael Mora Porras y de la escuela Saint Jude. Maestría. Universidad Estatal a distancia vicerrectoría académica. San José.

4. Durán , E., \& Basabe, M. (13 de diciembre de 2013). Salud mental y expresión de las emociones en el facebook. Recuperado el 24 de noviembre de 2015, de Dialnet: http://webcache.googleusercontent.com/search?q=cache:ZsGCVgwKdwJ:dialnet.unirioja.es/descarga/articulo/4800934.pdf+\& $\mathrm{cd}=1 \& \mathrm{hl}=\mathrm{es} \& \mathrm{ct}=\mathrm{clnk} \& \mathrm{gl}=\mathrm{mx}$

5. García, J., \& Delval, J. (2010). Psicología del desarrollo I. Madrid: UNED.

6. González, S. (2013). La promoción de libros impresos a través de de Twitter: análisis de los casos Ediciones Deusto, Gestión 2000 y Alienta Editorial. Obtenido de Recercat: https://ddd.uab.cat/pub/trerecpro/2013/hdl_2072_216935/Sara_Gonz alez_TFM.pdf

7. Hernández, G., \& Castro, A. (2014). Influencia de las redes sociales de internet en el rendimiento academico del area de informática en los estudiantes de los grados $8^{\circ}$ y $9^{\circ}$ del Instituto promoción social del norte de Bucaramanga. Tólima.

8. López, M., López, V., \& Galán, E. (2013). Redes sociales de internet $y$ adolescentes. Informe de los resultados de las pruebas. UCM Facultad de Educación y Formación del Profesorado.

9. Lozano, J. (2007). Teoría e investigación de la comunicación de masas (Segunda ed.). México: Pearson.

10. Molina, G., \& Toledo, R. (2014). Las redes sociales y su influencia en el comportamiento de los adolescentes. Cuenca.

11. Morris, C., \& Maisto, A. (2005). Introducción a la psicología. España: Pearson. 
12. Ochoa, P., \& Uribe, I. (2015). Sentido de la interacción social mediada por Facebook en un grupo de adolescentes, estudiantes de bachilleratos públicos de Colima, México. Epoca III, XXI(42).

13. Pascual, R. (2004). Sociedad de la información a la española. San Vicente: Club Universitario.

14. Raosoft. (2 de enero, 2018). Obtenido de raosoft: www.raosoft.com/samplesize.html

15. Rivadeneira, A. (2016). La teoría de los usos y gratificaciones aplicada a las redes sociales: análisis de la situación en estudiantes del colegio de bachillerato "Macas", de la ciudad de Macas, Provincia de Morona Santiago, año 2016 . Macas.

16. Serrano, J. (2016). Internet y emociones: nuevas tendencias en un campo de investigación emergente. Comunicar, XXIV (46).

17. Sosa, J., \& Arcila, C. (2013). Manual de Teoría de la Comunicación. Barranquilla: Universidad del Norte.

18. Torres, A., \& Vega, V. (2009). Creación, aparición y desarrollo de identidades en las redes virtuales. Licenciatura. Pontificia Universidad Javeriana. Bogotá.

19. Valderrama, R. (2013). De la escritura en Facebook a la escritura académica. Licenciatura. Universidad Pedagógica Nacional. México, DF.

20. West, R., \& Turner, L. (2005). Teoría de la Comunicación análisis y aplicación. Madrid: McGraw-Hill. 